Pacific Journal of Mathematics

PARTITIONS OF MASS-DISTRIBUTIONS AND OF CONVEX 


\section{PARTITIONS OF MASS-DISTRIBUTIONS AND OF CONVEX BODIES BY HYPERPLANES}

\section{B. GRÜNBAUM}

1. Introduction. The following results are well-known (Neumann [7]; Eggleston [3], [4, p. 125-126], [5, p. 118]; Newman [8]:

(A) For any mass-distribution in the plane, such that the total mass contained in every half-plane is finite and depends continuously on the position of the half-plane, there exists a point $P$ such that each half-plane which contains $P$, contains at least $1 / 3$ of the total mass.

(B) For any convex body $K$ in the plane there exists a point $P$ such that for each half-plane $H$ containing $P$ the area of $H \cap K$ is at least $4 / 9$ of the area of $K$.

The main object of the present note is to generalize (A) and (B) to higher-dimensional Euclidean spaces.

In the following $m$ shall denote a fixed (non-negative) finite measure on the ring of subsets of $E^{n}$ generated by the closed half-spaces in $E^{n}$. (For the terminology and results on measures see, e.g., Halmos [6].)

For a real $\lambda, 0 \leqq \lambda \leqq 1 / 2$, we define $\mathscr{C}(m, \lambda)$ as the subset of $E^{n}$ consisting of those points $P \in E^{n}$ which satisfy the condition: For any closed half-space $H \subset E^{n}$, with $P \in H$, the relation $m(H) \geqq \lambda \cdot m\left(E^{n}\right)$ holds.

Obviously, $\mathscr{C}(m, \lambda)$ is a compact, convex (possibly empty) set.

Using the notation of $\mathscr{C}(m, \lambda)$, Theorem (A) may be extended as follows:

THEOREM 1. $\mathscr{C}(m, 1 /(n+1)) \neq \phi$ for any measure $m$ in $E^{n}$.

Let $V(S)$ denote the volume ( $n$-dimensional Lebesgue measure) of the set $S \subset E^{n}$. For any convex body $K \subset E^{n}$, we denote by $m_{K}$ the measure (defined for all Lebesgue measurable subsets $S$ of $E^{n}$ ) obtained by taking $m_{K}(S)=V(S \cap K)$. We denote $\mathscr{C}\left(m_{K}, \lambda\right)$ by $\mathscr{C}(K, \lambda)$.

Theorem (B) may now be generalized as follows:

Theorem 2. If $K$ is any convex body in $E^{n}$ then

$$
\mathscr{C}\left(K,\left(\frac{n}{n+1}\right)^{n}\right) \neq \phi
$$

We shall prove Theorems 1 and 2 in the following two sections.

Received January 22, 1960. This research was supported by the United States Air Force through the Air Force Office of Scientific Research of the Air Research and Development Command, under contract No. AF49(638)-253. Reproduction in whole or in part is permitted for any purpose of the United States Government. 
The last section contains remarks and comments.

2. Proof of Theorem $1 .^{1}$ If $v$ is a unit vector (in $E^{n}$ ) and $\alpha$ is a real number, let $H(v, \alpha)$ be the closed half-space

$$
H(v, \alpha)=\left\{x \in E^{n} ;(x, v) \leqq \alpha\right\} .
$$

Let $\alpha(v)$ be defined by

$$
\alpha(v)=\min \left\{\alpha ; m(H(v, \alpha)) \geqq \frac{n}{n+1} m\left(E^{n}\right)\right\},
$$

(the minimum is attained since $m(H(v, \alpha))$ is continuous to the right as a function of $\alpha)$. Let $H(v)=H(v, \alpha(v))$ and

$$
H^{*}(v)=\left\{x \in E^{n} ;(x, v) \geqq \alpha(v)\right\} .
$$

(Without loss of generality we shall in the sequel assume $m\left(E^{n}\right)=1$.) Obviously,

$$
\mathscr{C}\left(m \frac{1}{(n+1)}\right) \supset \bigcap_{v} H(v)
$$

hence, if $\bigcap_{v} H(v) \neq \phi$ the proof is complete. On the other hand, if $\bigcap_{v} H(v)=\phi$, we shall show that

$$
C\left(m \frac{1}{(n+1)}\right) \neq \phi
$$

in the following way. The half-spaces $H(v)$ are closed convex sets, and it is easily seen that a finite number of them may be found such that their intersection is compact. By Helly's theorem on intersections of convex sets (see, e.g., Rademacher-Schoenberg [9]) the assumption $\bigcap_{v} H(v)=\phi$ implies the existence of an $n+1$ membered family of unit vectors $v_{i}, 0 \leqq i \leqq n$, such that $\bigcap_{i=0}^{n} H\left(v_{i}\right)=\phi$. Using an inductive argument it is easily seen that we may assume that every $n$ of the vectors $v_{i}$ are linearly independent. Therefore (denoting $H_{i}=H\left(v_{i}\right)$ and $\left.H_{i}^{*}=H_{i}^{*}\left(v_{i}\right)\right)$ the set $S=\bigcap_{i=0}^{n} H_{i}^{*}$ is a non-degenerate simplex whose faces are contained in the hyperplanes $H_{i} \cap H_{i}^{*}, 0 \leqq i \leqq n$. By the definition of $\alpha(v)$ we have $m\left(H_{i}^{*}\right) \geqq 1 /(n+1)$ and $m\left(\operatorname{Int} H_{i}^{*}\right) \leqq 1 /(n+1)$ for all $i$. Therefore $m\left(H_{j} \cap\right.$ Int $\left.H_{i}^{*}\right) \leqq 1 /(n+1)$, and thus $m\left(H_{j} \cap H_{i}\right) \geqq$ $(n-1) /(n+1)$ for all $i \neq j$. Now, since $\bigcap_{i=0}^{n} H_{i}=\phi$, we have

$$
\begin{aligned}
\frac{n}{n+1} & \geqq m\left(H_{i}\right) \geqq m\left[H_{i} \cap\left(\bigcup_{j \neq i} H_{j}\right)\right] \geqq \frac{1}{n-1} \sum_{\substack{0 \leq j \leq n \\
j \neq i}} m\left(H_{i} \cap H_{j}\right) \\
& \geqq \frac{1}{n-1} \cdot n \cdot \frac{n-1}{n+1}=\frac{n}{n+1} .
\end{aligned}
$$

1 The author is indebted to Professor B. M. Stewart for the correction of an error in the original proof. 
Thus, for all $i$, equality signs hold throughout. In particular,

$$
m\left(\bigcap_{\substack{0 \leq j \leq n \\ j \neq i}} H_{j}\right)=\frac{1}{n+1}
$$

for all $i$ (i.e., the support of $m$ is contained in the "vertex-regions" of the simplex $S=\bigcap_{i} H_{i}^{*}$ ), and it is immediately verified that

$$
\mathscr{C}\left(m ; \frac{1}{(n+1)}\right) \supset S \neq \phi .
$$

This ends the proof of Theorem 1.

3. Proof of Theorem 2. Let $G_{k}$ denote the centroid of the convex body $K \subset E^{n}$. We shall prove Theorem 2 by establishing the stronger statement $G_{K} \in \mathscr{C}\left(K, \alpha_{n}\right)$, where $\alpha_{n}=(n /(n+1))^{n}$. Assuming, to the contrary, that $G_{k} \notin \mathscr{C}\left(K, \alpha_{n}\right)$, there exists a hyperplane $L$ containing $G_{K}$ such that the volume of the part of $K$ contained in one of the halfspaces determined by $L$ is less than $\alpha_{n} \cdot V(K)$. We shall obtain a contradiction from this assumption.

Let $G_{K}$ be the origin of an orthogonal system of coordinates $\left(x_{1}\right.$, $\cdots, x_{n}$ ) of $E^{n}$, such that $L$ is the hyperplane determined by $x_{1}=0$.

Let $H^{+}$be the half-space $\left\{\left(x_{1}, \cdots, x_{n}\right) ; x_{1} \geqq 0\right\}$ and $H^{-}$the other closed half-space determined by $L$. We may assume that $V\left(K \cap H^{-}\right)<$ $\alpha_{n} \cdot V(K)$. For any set $S \subset E^{n}$ we shall use the notations $S^{-}=S \cap H^{-}$ and $S^{+}=S \cap H^{+}$. Let $\hat{K}$ be the set obtained from $K$ by spherical symmetrization ("Schwarzsche Abrundung", Bonnesen-Fenchel [1, p. 71]; "Schwarz rotation process", Eggleston [5, p. 100]) with respect to the $x_{1}$-axis (i.e., $\hat{K}$ is the union of the $(n-1)$-dimensional spheres obtained by taking in each hyperplane $L_{t}=\left\{\left(x_{1}, \cdots, x_{n}\right) ; x_{1}=t\right\}$ an $(n-1)$ dimensional sphere with center $(t, 0, \cdots, 0)$ and $(n-1)$-dimensional volume equal to that of $\left.K \cap L_{t}\right)$. It is well known that $\hat{K}$ is a convex body, and obviously $V\left(\hat{K}^{-}\right)=V\left(K^{-}\right), \quad V\left(\hat{K}^{+}\right)=V\left(K^{+}\right)$and $G_{\hat{K}}=G_{K}$. Therefore $V\left(\hat{K}^{-}\right)<\alpha_{n} \cdot V(\hat{K})$ and $G_{\hat{K}} \notin C\left(\hat{K}, \alpha_{n}\right)$. Let $C^{-}$denote the (orthogonal) hypercone with base $\hat{K} \cap L$ and vertex $(c, 0, \cdots, 0) \in H^{-}$, where $c$ is chosen in such a way that $V\left(C^{-}\right)=V\left(\hat{K}^{-}\right)$. Let $C$ be the hypercone obtained by extending $C^{-}$(along its generators) into $H^{+}$in such a way that $V\left(C^{+}\right)=V\left(\hat{K}^{+}\right)$. With $C$ thus defined, it is easily verified that the $x_{1}$-coordinate of $G_{O^{-}}\left(\right.$resp. $G_{\sigma^{+}}$) is not greater than that of $G_{\hat{\mathbf{K}}^{-}}$(resp. $G_{\hat{K}^{+}}$). Therefore, $G_{0} \in H^{-}$, and thus the hyperplane $L^{*}$, parallel to $L$ and passing through $G_{o}$, divides $C$ into two parts in such a way that the part contained in $H^{-}$has a volume smaller than $\alpha_{n} \cdot V(C)$. But by a simple computation we find (since the centroid of a hypercone divides its height in the ratio $1: n$ ) that the volume in question equals $\alpha_{n} \cdot V(C)$. The contradiction reached proves the theorem. 
4. Remarks. (i) It is very easy to find examples which show that the bounds in Theorems 1 and 2 are the best possible. From the proofs given, it is also easy to deduce that if $\mathscr{C}\left(K, \alpha_{n}+\varepsilon\right)=\phi$ for all $\varepsilon>0$ then $K$ is a simplex, and that $\mathscr{C}(m, 1 /(n+1)+\varepsilon)=\phi$ for all $\varepsilon>0$ only if the support of $m$ is contained in the "vertex-regions" of some (possibly degenerate) simplex, and all the "vertex-regions" have the same measure.

(ii) The proof of Theorem 1 may be somewhat simplified if the measure $m$ is assumed to be continuous (as in Theorem (A)). The advantage of the more general form is that it includes, e.g., measures generated by finite point-sets, surface-area etc.

(iii) The following obvious corollary of Theorem 2 is interesting because of its independence on the dimension:

For any convex body $K \subset E^{n}$ we have

$$
G_{K} \in \mathscr{C}\left(K, e^{-1}\right)=C(K, 0.3678 \cdots) .
$$

(iv) It would be interesting to find the analogue of Theorem 2 obtained by substituting the $(n-1)$-dimensional surface area $A(K)$ for the volume $V(K)$ of $K \subset E^{n}$. The problem seems to be unsolved even for $n=2$.

(v) It is easily proved that for any continuous mass-distribution in the plane there exists a pair of orthogonal lines such that each "quadrant" determined by them contains $1 / 4$ of the total mass. The analogous statement is not true for $n$ mutually orthogonal hyperplanes in $E^{n}$; does it become true if the condition of orthogonality is omitted?

(vi) It is well known (Buck and Buck [2]) that for any continuous mass-distribution in the plane there exist three concurrent straight lines such that each of the six "wedges" determined by them contains $1 / 6$ of the total mass. Does this fact generalize to $E^{n}$ when the three lines are replaced by $n+1$ hyperplanes with a common $(n-2)$-dimensional intersection?

Added in proof. After submitting the present note for publication, the following facts came to our attention:

(i) Theorems (A) and B are proved, and Theorem 1 suggested, in I. M. Jaglom-W. G. Boltjanski, Konvexe Figuren, Berlin, 1956, pp. 16, $18,27,104-106,116,135-136$ (this is a translation of the Russian original, which appeared in 1951); Theorem (b) is there attributed (without references) to A. Winternitz.

(ii) A proof of Theorem 1 (using Brouwer's fixed-point theorem), together with some related results, was given in B. J. Birch, On $3 \mathrm{~N}$ points in a plane, Proc. Cambridge Philos. Soc., 55 (1959), 289-293.

(iii) A proof of Theorem 2, very similar to the one given in the 
present paper, was found independently by P. C. Hammer; it is contained in a paper "Volumes cut from convex bodies by planes", submitted to "Mathematika".

(iv) The relation $\mathscr{C}\left(m, \frac{1}{2}\right) \neq \phi$ (resp. $\mathscr{C}\left(\mathrm{K}, \frac{1}{2}\right) \neq \phi$ holds for any distribution of masses (resp. convex body) with a center of symmetry. Obviously, $\mathscr{C}\left(m, \frac{1}{2}\right) \neq \phi$ is possible also for mass-distributions without a center. The conjecture (trivial for the plane) that $\mathscr{C}\left(K, \frac{1}{2}\right) \neq \phi$ characterizes centrally symmetric convex bodies was first established Professor F. J. Dyson; it is hoped that a proof will be published soon.

(v) Results generalizing Theorem 1 were established by R. Rado in the paper, "A theorem on general measure", J. London Math. Soc., 21 (1946), 291-300. Rado's proof also uses Helley's theorem, but in a fashion different from the one used in the present paper.

\section{REFERENCES}

1. T. Bonnesen and W. Fenchel, Theorie der konvexen Körper, Springer, 1934.

2. R. C. Buck and E. F. Buck, Equipartition of convex sets, Mathematics Magazine, 22 (1949), 195-198.

3. H. G. Eggleston, Some properties of triangles as extremal convex curves, Journ. London Math. Soc., 28 (1953), 32-36.

4. - Problems in Euclidean space: Application of Convexity, Pergamon Press 1957.

5. - Convexity, Cambridge Tracts in Math. and Math. Phys., No. 47, Cambridge 1958.

6. P. Halmos, Measure theory, Van Nostrand 1950.

7. B. H. Neumann, On an invariant of plane regions and mass distributions, Journ. London Math. Soc., 20 (1945), 226-237.

8. D. J. Newman, Partitioning of areas by straight lines, Abstract 548-108. Notices Amer. Math. Soc., 5 (1958), 510.

9. H. Rademacher and I. J. Schoenberg, Helly's theorems on convex domains and Tchebycheff's approximation problem, Canad. Journ. Math., 2 (1950), 245-256.

INSTITUTE FOR ADVANCED STUDY 



\section{PACIFIC JOURNAL OF MATHEMATICS}

\section{EDITORS}

David GILbarg

Stanford University

Stanford, California

\section{F. H. BRowneLL}

University of Washington

Seattle 5, Washington

\section{A. L. Whiteman}

University of Southern California Los Angeles 7, California

\section{J. PAIGe}

University of California

Los Angeles 24, California

\section{ASSOCIATE EDITORS}
E. F. BECKENBACH
T. M. CHERRY
D. DERRY

\author{
E. HEWITT \\ A. HORN \\ L. NACHBIN
}

\author{
M. OHTSUKA \\ H. L. ROYDEN \\ M. M. SCHIFFER
}

E. SPANIER

E. G. STRAUS

F. WOLF

\section{SUPPORTING INSTITUTIONS}

\author{
UNIVERSITY OF BRITISH COLUMBIA \\ CALIFORNIA INSTITUTE OF TECHNOLOGY \\ UNIVERSITY OF CALIFORNIA \\ MONTANA STATE UNIVERSITY \\ UNIVERSITY OF NEVADA \\ NEW MEXICO STATE UNIVERSITY \\ OREGON STATE COLLEGE \\ UNIVERSITY OF OREGON \\ OSAKA UNIVERSITY \\ UNIVERSITY OF SOUTHERN CALIFORNIA
}

\author{
STANFORD UNIVERSITY \\ UNIVERSITY OF TOKYO \\ UNIVERSITY OF UTAH \\ WASHINGTON STATE COLLEGE \\ UNIVERSITY OF WASHINGTON \\ AMERICAN MATHEMATICAL SOCIETY \\ CALIFORNIA RESEARCH CORPORATION \\ HUGHES AIRCRAFT COMPANY \\ SPACE TECHNOLOGY LABORATORIES \\ NAVAL ORDNANCE TEST STATION
}

\footnotetext{
Mathematical papers intended for publication in the Pacific Journal of Mathematics should be typewritten (double spaced), and the author should keep a complete copy. Manuscripts may be sent to any one of the four editors. All other communications to the editors should be addressed to the managing editor, L. J. Paige at the University of California, Los Angeles 24, California.

50 reprints per author of each article are furnished free of charge; additional copies may be obtained at cost in multiples of 50 .
}

The Pacific Journal of Mathematics is published quarterly, in March, June, September, and December. The price per volume (4 numbers) is $\$ 12.00$; single issues, $\$ 3.50$. Back numbers are available. Special price to individual faculty members of supporting institutions and to individual members of the American Mathematical Society: $\$ 4.00$ per volume; single issues, $\$ 1.25$.

Subscriptions, orders for back numbers, and changes of address should be sent to Pacific Journal of Mathematics, 2120 Oxford Street, Berkeley 4, California.

Printed at Kokusai Bunken Insatsusha (International Academic Printing Co., Ltd.), No. 6, 2-chome, Fujimi-cho, Chiyoda-ku, Tokyo, Japan.

PUBLISHED BY PACIFIC JOURNAL OF MATHEMATICS, A NON-PROFIT CORPORATION

The Supporting Institutions listed above contribute to the cost of publication of this Journal, but they are not owners or publishers and have no responsibility for its content or policies. 


\section{Pacific Journal of Mathematics}

\section{Vol. 10, No. $4 \quad$ December, 1960}

M. Altman, An optimum cubically convergent iterative method of inverting a linear bounded operator in Hilbert space . . . . . . . . . . . . . . . . . . . . . . . . . . 1107

Nesmith Cornett Ankeny, Criterion for rth power residuacity ................. 1115

Julius Rubin Blum and David Lee Hanson, On invariant probability measures I . . . . . 1125

Frank Featherstone Bonsall, Positive operators compact in an auxiliary topology ..... 1131

Billy Joe Boyer, Summability of derived conjugate series . . . . . . . . . . . . . . . . 1139

Delmar L. Boyer, A note on a problem of Fuchs . . . . . . . . . . . . . . . . . 1147

Hans-Joachim Bremermann, The envelopes of holomorphy of tube domains in infinite

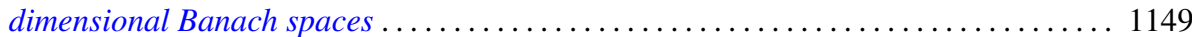

Andrew Michael Bruckner, Minimal superadditive extensions of superadditive

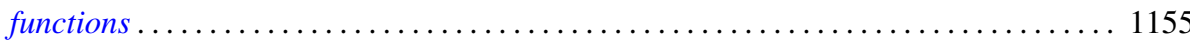

Billy Finney Bryant, On expansive homeomorphisms .................... 1163

Jean W. Butler, On complete and independent sets of operations in finite algebras . . . . . 1169

Lucien Le Cam, An approximation theorem for the Poisson binomial distribution ...... 1181

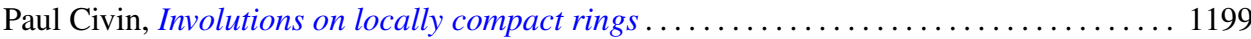

Earl A. Coddington, Normal extensions of formally normal operators . . . . . . . . . 1203

Jacob Feldman, Some classes of equivalent Gaussian processes on an interval ........ 1211

Shaul Foguel, Weak and strong convergence for Markov processes . . . . . . . . . . . 1221

Martin Fox, Some zero sum two-person games with moves in the unit interval ........ 1235

Robert Pertsch Gilbert, Singularities of three-dimensional harmonic functions . . . . . . . 1243

Branko Grünbaum, Partitions of mass-distributions and of convex bodies by

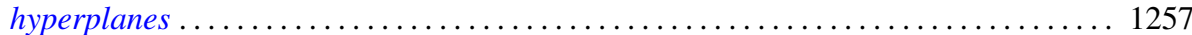

Sidney Morris Harmon, Regular covering surfaces of Riemann surfaces ........... 1263

Edwin Hewitt and Herbert S. Zuckerman, The multiplicative semigroup of integers

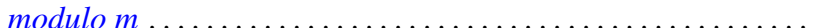

Paul Daniel Hill, Relation of a direct limit group to associated vector groups . ......... 1309

Calvin Virgil Holmes, Commutator groups of monomial groups . .

James Fredrik Jakobsen and W. R. Utz, The non-existence of expansive homeomorphisms

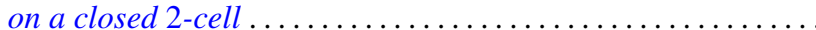

John William Jewett, Multiplication on classes of pseudo-analytic functions . . . . . . . 1323

Helmut Klingen, Analytic automorphisms of bounded symmetric complex domains . . . . 1327

Robert Jacob Koch, Ordered semigroups in partially ordered semigroups . . . . . . . . 1333

Marvin David Marcus and N. A. Khan, On a commutator result of Taussky and

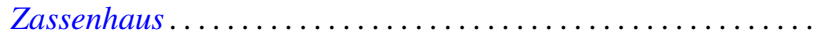

John Glen Marica and Steve Jerome Bryant, Unary algebras......

Edward Peter Merkes and W. T. Scott, On univalence of a continued fraction . . . . . . . 1361

Shu-Teh Chen Moy, Asymptotic properties of derivatives of stationary measures . . . . . 1371

John William Neuberger, Concerning boundary value problems . . . . . . . . . . . 1385

Edward C. Posner, Integral closure of differential rings . . . . . . . . . . . . . . . . . 1393

Marian Reichaw-Reichbach, Some theorems on mappings onto . . . . . . . . . . . . . 1397

Marvin Rosenblum and Harold Widom, Two extremal problems . . . . . . . . . . . . . . . . 1409

Morton Lincoln Slater and Herbert S. Wilf, A class of linear differential-difference

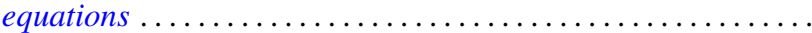

Charles Robson Storey, Jr., The structure of threads . . . . . . . . . . . . . . . . . . 1429

J. François Treves, An estimate for differential polynomials in $\partial / \partial z_{1},, \cdots, \partial / \partial z_{-} n \ldots \ldots 1447$

J. D. Weston, On the representation of operators by convolutions integrals . . . . . . . . 1453

James Victor Whittaker, Normal subgroups of some homeomorphism groups ......... 1469 